\title{
LA TRADUCCIÓN AL ESPAÑOL DE CUENTOS DE COLORES DE IMANTS ZIEDONIS
}

\author{
MIGUEL ÁNGEL PÉREZ SÁNCHEZ
}

Universidad de Letonia, Letonia

\begin{abstract}
Resumen. Krāsainās pasakas, título que en español se traduciría como Cuentos de colores, ha continuado siendo hasta nuestros días una de las obras más populares de Imants Ziedonis desde que saliera a la luz en 1973. Este conjunto de miniaturas líricas, cada una de las cuales tiene por objeto un color, estaba en principio dirigido al público infantil, y en él el poeta letón desplegó un rico abanico de figuras estilísticas cuyo propósito era el de contribuir a la elaboración de una literatura que mediante el juego, la belleza y la inteligencia sirviese a la formación del niño. Entre estas figuras destacan a lo largo del texto por su recurrencia y variedad los epítetos, paradojas, comparaciones y paralelismos que entretejen una realidad sutilmente absurda y deliciosamente divertida. La tarea de verter al español una tal densidad estilística manteniendo la fidelidad al original a la par que su elegancia y naturalidad no ha sido siempre fácil. La Retórica General tal como ha sido reinterpretada en todas sus operaciones por Antonio García Berrio y Tomás Albadalejo, el alcance del Materialismo Filosófico en cuanto sistema filosófico capaz de dar cuenta de la realidad en toda su amplitud y traductología de autores como Nida, Newmark, Vlakov y Florin y Hurtado Albir nos servirán para dar cuenta de algunos de los problemas que presenta la adaptación al español del texto de Ziedonis.
\end{abstract}

Palabras clave: Cuentos de colores, materialismo, retórica, traducción, Ziedonis

\section{INTRODUCCIÓN}

Imants Ziedonis (1933-2013) forma, junto Aleksandrs Čaks (1901-1950) y Ojārs Vācietis (1933-1983), la tríada de poetas en letón más significativos del siglo XX. Cada uno de ellos define con su estilo y presencia una época de la literatura en esta lengua, de manera que no hay referencia posible a ella ni manera de entenderla sin contar con cualquiera de los tres. En este artículo daremos cuenta de algunas cuestiones en torno a la traducción de la prosa poética del más joven de ellos.

Imants Ziedonis publicó diversas colecciones de cuentos entre los años 1973 y 1997: Krāsainās pasakas, Lāču pasaka, Blēnas un pasakas y, por último, Pasakas par bizi, la colección que más difiere del resto tanto por su estilo como por la temática que trata: el suicidio. Al mismo tiempo que escribía para los niños 
también publicó algunos escritos sobre los problemas de la literatura dirigida al público infantil en los que además analizaba la producción de sus coetáneos.

Ziedonis entendía que las principales características de la buena literatura infantil debían ser la belleza y la inteligencia, así como la capacidad para hacer pensar al niño y provocarle un sentimiento de felicidad y satisfacción:

Para que el trabajo fuese productivo y no carente de objeto, y para que la obra no sufriese de la ciega admiración que produce la belleza, sino que se tomase en cuenta también su valor ético, categorías como las de belleza e inteligencia debían ir de la mano, pues sin esos factores el principio necesario que hace del juego base para la capacidad de comprensión de los niños no funciona: el juego solo es placentero para quien conoce las reglas del juego, y eso ya es una forma de sabiduría. (Zālīte, 2009: 138; esta traducción y siguientes son del autor)

En este artículo nos centraremos en una de las colecciones de cuentos infantiles más celebradas de Ziedonis, Krāsainās pasakas (Cuentos de colores), y en cómo algunas de las características anteriormente reseñadas, el juego y su manifestación estética, dan lugar en la traducción a diversos problemas de carácter material y formal para cuya resolución proponemos la introducción de variables filosóficas en el análisis textual.

\section{ALGUNAS CUESTIONES SOBRE TRADUCCIÓN}

Traducir consiste en reproducir, de la manera más aproximada y natural posible, un mensaje dado en una lengua original a una lengua receptora, y esto en dos niveles complementarios: el del sentido (nivel material) y el del estilo (nivel formal), siendo ambos disociables, a propósito de su análisis y clasificación, pero no separables.

La traducción debe atender en primer lugar al sentido del texto: debe reproducir el mensaje en su nivel material con la mayor fidelidad posible, pero la reproducción de cualquier mensaje hace inevitable el paso por el nivel formal a través de una serie de operaciones gramaticales y léxicas.

Como aporte a la teoría de la traducción literaria creemos que las herramientas que proporciona la Retórica Clásica tal como ha sido reinterpretada en las últimas décadas por Antonio García Berrio (1984) y Tomás Albadalejo (1993) a modo de una Retórica General que recupere todas las operaciones tradicionales de construcción textual: Inventio (Invención), Dispositio (Disposición) y Elocutio (Elocución), constituyen una referencia fundamental que no ha sido tomada en consideración por la traductología actual. Estas tres operaciones, que se articulan en términos macro- y microtextuales (siendo la Invención dada como estructura profunda del texto o res extensional, la Elocución como microestructura o Verba, y la Disposición como aquella operación en la que confluyen las dos anteriores), dan lugar a una completa reinterpretación del texto. 
En general, los aspectos de la Invención y Disposición no van a provocar en la traducción problemas de calado en cuanto se refieran a la cuestión de los géneros, y esto cuando la traslación se produzca entre culturas distantes (por ejemplo, las del área de influencia greco-romana en relación con las del área de influencia sinonipona), o entre épocas muy alejadas de una misma cultura (la épica homérica, por ejemplo, en relación con los siglo XIX y XX donde la poesía épica ha sido sustituida prácticamente en absoluto por la novela). Mayor es el problema que surge a partir de la traslación de aspectos culturales (Res) y su plasmación formal a modo de estilo (entendido estilo como el uso autorial del ornato en un proceso en el que figuras y tropos constituyen fundamento inexcusable de su sistema de construcción).

La traducción no solo se produce entre lenguas distintas sino también entre culturas distintas; es, pues, intercultural. El trasvase de la información extensional e intensional que constituye la Res o estructura semántica de la realidad propia de una sociedad realmente existente localizada en un espacio y tiempo precisos es uno de los principales problemas al que ha de enfrentarse el traductor.

Nida (1945) propuso clasificar los diversos ámbitos culturales en cinco grupos: ecología, cultura material, social, religiosa y lingüística. De esta división no se entiende ni la presencia del medio transmisor de la cultura (el lenguaje) junto al resto de esferas ni la distinción ente ecología y cultura material, como si la ecología no estuviera ya intervenida por la mano del hombre.

Vlakhov y Florin (1970) propusieron el uso del término realia para referirse a los rasgos textuales que aluden a elementos de la realidad externa y cuya función es la de proporcionar color histórico o local. Distinguieron cuatro tipos: geográfico-etnográficos, folclóricos, objetos de la vida cotidiana y elementos sociohistóricos. En esta clasificación la separación entre etnografía, vida cotidiana y sociedad carece de sentido, por cuanto no resulta inteligible en qué medida podría deslindarse la etnografía de la sociología en términos textuales, qué son objetos de la vida cotidiana y qué los separa de los dos grupos anteriores (¿cómo podrían darse unos sin otros?) qué perspectiva podría asumir el autor del texto desde una perspectiva folclórica.

Newmark (1992: 133-146) introduce, junto a las categorías propuestas por Nida, la gestual, y al margen del interés que supone el añadido de elementos paralingüísticos, su clasificación sufre los mismos problemas que la de Nida.

Katan (1999: 45) realiza una propuesta claramente intervenida por el psicologismo y el subjetivismo de carácter postmoderno. Distingue entre el entorno físico y político, la conducta, las capacidades y estrategias comunicativas, los valores, las creencias y la identidad.

Por último, Vermeer (1983) propone el concepto de culturema, que retomado por Nord (1997: 34) define como 'un fenómeno social de una cultura X que es entendido como relevante por los miembros de esa cultura y que, comparado con un fenómeno correspondiente de una cultura $Y$ es percibido como específico de la cultura X'. Este concepto nos servirá para establecer una nueva clasificación 
cruzada de rasgos culturales a partir de los espacios Ontológico, Antropológico y Religioso del Materialismo Filosóficos que estimamos más estricta y con mayor poder explicativo.

\section{EL MATERIALISMO FILOSÓFICO Y SUS ESPACIOS}

El Materialismo Filosófico constituye el sistema filosófico desarrollado por el filósofo español Gustavo Bueno Martínez (1924-2016) a lo largo de varias décadas y una amplia producción bibliográfica. Podemos definirlo como una doctrina sobre la estructura de la realidad que se caracteriza por su oposición al materialismo monista y al idealismo.

El mundo (o mundus adspectabilis) del que da cuenta el plano de la Ontología especial se estratifica en tres órdenes o géneros de materialidad entre los que, para evitar el monismo teológico del 'todo está conectado con todo', se dan conexiones y desconexiones según el principio platónico de Symploké (Bueno, 1992/1993: 563-568).

Tanto la Ontología como la Gnoseología materialista están determinadas en función del espacio antropológico, pues este espacio abarca el mundo conceptualizado por entero y presupone la idea de que el hombre no existe de manera aislada, sino que actúa junto a otras entidades humanas y está envuelto por realidades no antropológicas, ya se trate de realidades orgánicas (plantas, animales) o inorgánicas (piedras, astros). Bueno coordina este espacio antropológico en tres ejes: eje circular, eje radial y eje angular.

El eje circular del espacio antropológico comprende las relaciones del hombre consigo mismo, pero no del hombre en abstracto, sino de individuos históricos dados en sociedades múltiples y heterogéneas (egipcios, romanos, celtas, chinos...). Estas relaciones serán no solo de tipo social o psicológico, sino también de orden político, jurídico, económico, etc.

El eje radial del espacio antropológico comprende las relaciones ya no del hombre consigo mismo, sino del hombre con términos no antropológicos como los denominados entes de naturaleza (la tierra, el agua, el aire, el fuego) y que pese a entenderse como entes físicos o biológicos, están desprovistos de inteligencia.

El eje angular del espacio antropológico comprende, por último, las relaciones del hombre con otros entes que no son hombres, pero que tampoco son parte de la naturaleza, y con los que median relaciones de amistad o de temor de acuerdo a un comportamiento que aunque no esté exento de error, tampoco es imaginario. A estos entes se les denomina desde el Materialismo Filosófico númenes (Bueno, 1996: 97).

Las relaciones en el eje angular del espacio antropológico con entidades inteligentes no humanas sirven como fundamento a una teoría de la religión. Estas entidades envuelven efectivamente al ser humano enfrentándose a él o ayudándole, ya sea en forma de seres maléficos o bienhechores, y en ellas se encuentra el núcleo de la religión, y no en experiencias de tipo alucinatorio o en la 
existencia de Dios como fundador de religiones, puesto que la idea de Dios sería un anacronismo aplicada al hombre prehistórico.

Si bien en estas bestias teriomorfas estarían en el núcleo de las religiones humanas, parte de ellas no se habrían detenido en esa fase sino que como el judaísmo, el cristianismo, el islam o el hinduismo, habrían pasado por sucesivas fases que conformarían el curso de las religiones y de las que se distinguen fundamentalmente tres: primaria, secundaria y terciaria.

Las religiones primarias serían las que, como queda dicho, giran en torno a la simbolización del animal que desde época paleolítica es contemplado no ya como objeto de caza, sino como arquetipo al que rogar o engañar y cuya esencia, tras su desaparición fenoménica, persiste.

Las religiones secundarias nacerían en el neolítico a partir de cambios tecnológicos que agotarían la caza y darían lugar a la domesticación de los animales. Durante este periodo las figuras numinosas sufrirían una transformación mediante la que los animales dejarían de ser identificables como tales para convertirse en otro tipo de entidades a los que se denominará dioses, pero que, como en el caso del dios egipcio Horus, al que se representaba con cabeza de halcón, o de la diosa griega Palas Atenea, a la que se solía representar junto a un mochuelo, seguían manteniendo atributos animales.

Las religiones terciarias, por último, reinterpretarían críticamente la fase anterior hasta reducir el delirio politeísta a un monoteísmo metafísico.

\section{CRITERIOS Y ESTRATEGIAS PARA LA TRANSFERENCIA DE CULTUREMAS}

Dentro de una perspectiva funcional y dinámica, en la que se conjugue textualidad con una interpretación filosófica de la realidad ontológica y antropológica, proponemos una reinterpretación de las técnicas señaladas por Hurtado Albir (2001: 614-615) en la traducción de culturemas. Entre estas técnicas se encontrarían la adaptación, la amplificación, la generalización, la elisión y el préstamo. Cada una de ellas la reinterpretaremos en términos culturales a partir del cruce de los espacios que constituyen la realidad del hombre tal como los estudia el Materialismo Filosófico (por simplificación, subsumimos en este capítulo el espacio religioso en el antropológico).

La adaptación consiste en reemplazar un elemento cultural de la Cultura de Origen (CO) por otro propio de la Cultura Receptora (CR); por ejemplo, cambiar en una traducción el baseball por el fútbol (Hurtado, 2001: 269) Supone una falta de correspondencia en el espacio antropológico del MF. Es decir, ambos conceptos aluden a realidades conocidas en ambas culturas, pero antropológicamente en una de ellas es ajena o carece de relevancia.

La amplificación consiste en el uso de más elementos lingüísticos en la traducción. Por ejemplo, río Gauja por Gauja. Supone, al igual que la adaptación, correspondencia en el espacio ontológico (es una realidad, la de los ríos, 
existente en ambas culturas), pero falta de ella en el espacio antropológico (el río en cuestión debe ser señalado como río, pues se lo desconoce como tal). Se diferencia, sin embargo, de la adaptación en que retóricamente el procedimiento de la amplificación tiene carácter estilístico (es decir, pertenece a la operación de Elocutio, a la Verba) frente al de la adaptación que se despliegue en el territorio de la Res, esto es, de la Inventio.

La generalización se manifiesta en el empleo de un término más general o neutro: el inglés a pint por una cerveza. En el caso de la generalización, la realidad cultural carece de equivalencia ontológica en una de las dos culturas y se sustituye por una realidad onto-antropológica equivalente. En letón sèta significa cerca, con correspondencia ontológica en español, pero normalmente en la literatura letona sèta se emplea como sinécdoque de patio, corral o en general de todo lo que forma parte del interior de una casa de campo frente al exterior.

La elisión es el procedimiento que consiste en eliminar elementos informativos del texto original en el texto receptor, porque por motivos estilísticos o dispositivos (sintáctico-textuales) el traductor se vea obligado a condensar o desplazar información contenida en un pasaje. Cuando la eliminación se hace de un culturema, esta se deberá según nuestra propuesta a falta de correspondencia total entre los espacios ontológico y antropológico de ambas lenguas, tratándose en el segundo espacio de una realidad inoperante. Por ejemplo, la distinción semántica que hace el letón entre los verbos iet (ir a pie) y braukt (ir en un vehículo) es a menudo innecesario mantenerla en su traducción al español.

Por último, el préstamo, funciona como contrapartida de la elisión, cuando en lugar de evitar el culturema cuya omisión provocaría algún tipo de incongruencia en la macroestructura textual (la Res), se utiliza directamente, sin traducirlo. Nos encontramos en este caso con el trasvase de realidades ontológicas entre culturas que las desconocen y que solo por presión social o económica las adoptarán antropológicamente. Los préstamos en nuestros días del inglés al español son continuos y su adopción no puede entenderse fuera del actual orden de capitalismo triunfante: smartphone, tablet, etc. Entre lenguas sin influencia antropológica mutua como el español y el letón el préstamo supondrá siempre un cierto grado de incomprensión y a menudo requerirá de una paráfrasis explicatoria.

Además todo lo indicado anteriormente, deberemos tener en cuenta el género textual en que el culturema se inserta: una metáfora culinaria no tendrá la misma función en un texto literario, donde puede servir a un propósito estético o humorístico, que en un texto etnográfico; el peso del culturema en la macroestructura textual y su implicación en la microestructura (en poesía habrá que tener en cuenta efectos rítmicos y prosódicos); la intención pragmática con que el culturema se emplee (registro, grado de novedad, universalidad, etc.) y las características del destinatario, tanto del lector original como del receptor de la traducción (el receptor de un cuento infantil será probablemente en ambos casos un niño). 
Ejemplificaremos este esquema interpretatorio a partir de algunos ejemplos extraídos de la prosa infantil de Imants Ziedonis.

\section{ALGUNOS PROBLEMAS FORMALES Y MATERIALES DE LOS CUENTOS DE COLORES DE IMANTS ZIEDONIS}

Ziedonis pone en práctica en sus obras dirigidas al público infantil el recurso del juego a través del lenguaje. Los juegos de palabras son tan numerosos y recurrentes en sus cuentos que en el nivel microestructural, el de la operación elocutiva formalizada a través de figuras y tropos, aparecen una densidad tal que solo a través de él se manifiesta el sentido de la narración en el nivel macroestructural. Los Cuentos de colores son fundamentalmente miniaturas líricas con gusto por la improvisación y cuyo núcleo lo constituye la demostración de sus ricas posibilidades; en ese campo de juego la nueva realidad todavía no logra concretarse y estabilizarse como realidad prosística, quedando en el nivel de la organización lírica.

En el Cuento blanco dominan los epítetos y las paradojas basadas en la inversión: objetos culturales de color negro, por ejemplo, se entienden como blancos: la tinta blanca, el pan blanco, el café blanco y el betún blanco. Las repeticiones se resuelven en un eje sintáctico-formal y semántico-fenoménico (Verba) cuyos referentes (Res) pertenecen al eje radial del espacio antropológico (gallo blanco, canción blanca, blanco día...) Las inversiones se resuelven en un nivel pragmático como culturemas y puesto que los culturemas se sitúan en el eje circular del espacio antropológico, no presentan tampoco ningún problema de traducción: tinta blanca, café blanco, betún blanco...El único culturema dado en el eje radial es de carácter topológico. Aparece dos veces en el texto: El río Gauja, a la rivera del Gauja.

En el Cuento negro dominan los epítetos, las paradojas basadas en la inversión (leche negra, azúcar negro, agua negra), las paremias y las cadenas de asociaciones. Los epítetos forman cadenas asociativas: 'Velnu bērni lasa melnas grāmatas melniem burtiem - pilnīgi melnas grāmatas' (Los niños endemoniados leen libros negros de negras letras: unos libros por completo negros) (Ziedonis, 2016: 21), cadena que en la traducción, como puede apreciarse, no ha sido posible resolver adecuadamente: negro, que es el color dominante en el cuento, carece de correlato fónico con el que aliterar en el campo léxico del diablo o demonio. Nos mantenemos, sin embargo, en un nivel formal. Otra cadena asociativa como 'pie velniem viss notiek otrādi. Pienu viṇi dzer melnu, cukuru grauž melnu. Ūdens pie viniem ir melns. Melna mute jāmazgā ar melnu ùdeni. Lai neviena balta plankumiņa nebūtu' (Entre demonios todo pasa de una manera distinta. La leche se la beben negra y el azúcar se lo toman negro. También el agua es negra. Sus negras bocas han de limpiárselas con agua negra: que no quede ni una mancha blanca) (Ziedonis, 2016: 22), presenta, como en el caso del Cuento blanco, una serie de paradojas que provienen del eje circular del espacio antropológico y su traducción no tiene consecuencias en el nivel formal ni en el material. Por 
último, en el caso de las paremias, encontramos: 'tumšs kā ellè (oscuro como el infierno) y 'nelabs kā velns' (malo como el diablo). La primera debería resolverse con un equivalente como 'oscuro como boca de lobo'. Ambas paremias proceden del eje angular del espacio antropológico, pero la original se resuelve en un nivel teológico (de religión terciaria) y la traducción, por adaptación, en el nivel de una religión primaria. La segunda, en cambio, tiene equivalente exacto: malo como un demonio.

Por último, en el Cuento rojo domina una red compacta de diminutivos, sinónimos en serie del lexema llama, descripciones poéticas del fuego y personificaciones. Para su traducción, de acuerdo a nuestra propuesta, hemos requerido para las personificaciones, aprovechando que el término letón usado aquí en tanto que epíteto y nombre propio coincide en cierto grado con la etimológica en español del nombre propio Candela (de Virgen de la Candelaria) y el objeto de iluminación candela, su adaptación antropológica (Candela por Liesmina); estas adaptaciones dependen además, en el nivel microestructural, de una serie de sinónimos encadenados que estilísticamente deben respetarse y no someterse a elisión, pues con ellos se estropearía el objetivo estético-lúdico que Ziedonis alcanza en el texto original. La solución, como decimos, la encontramos en la dualidad (como nombre propio y objeto) que contiene el lexema candela. Sirva el siguiente fragmento de ejemplo a lo indicado:

Liesmiña. Guntiņa. Ugunsmeitiņa. Kāda sarkana, skaista deg sveces galā! Cik paklausīga, cik mịla! Labulīe, liesmin̦a, ugunsmeitin̦a, kāda skaista, sarkana... Sarkana micīte, sarkanas kurpes kājās, ar sarkanu kabatas lakatinuu vēdinās. Laizās, sarkanu mēlìti rāda. Sarkani vaidziņi, karstumā piesarkuši. Skaistiņa, paklausigga, Guntiņa, ugunsmeitina. (Candela, Candelita, Candelaria, iqué roja y hermosa arde al cabo de la vela tu llama! ¡Tan modosita, tan cariñosa! Cosita, Candelita, Candelaria, qué linda, qué roja... Roja caperucita con zapatos rojos y un pañuelo rojo que al aire agita. Se relame y la lengua enseña. Rojas mejillas por el calor encendidas. Bonita, modosita, Candelaria, Candelita). (Ziedonis, 2016: 35)

\section{CONCLUSIONES}

Mediante la coordinación en un nivel microestructural de las posibilidades estilísticas del lenguaje (lo que en términos retóricos se conoce como Verba) con las realidades macroestructurales (en términos retóricos, Res) que de acuerdo a los espacios ontológico, antropológico (y dentro de él el religioso) define la doctrina del Materialismo Filosófico, hemos descrito y ejemplificado a lo largo de este breve artículo las posibilidades que para la traducción de los culturemas ofrece este sistema en dos niveles. Creemos que enriquecer la tradición traductológica, que es en lo fundamental, textual, con una propuesta en la que se sistematizan las operaciones ontológicas y antropológicas que todo traductor, consciente $o$ 
inconscientemente, lleva a cabo a lo largo de su labor, es de plena actualidad y de urgente atención por parte de los especialista en la materia.

\section{REFERENCIAS BIBLIOGRÁFICAS}

Albadalejo, T. (1993) Retórica. Madrid: Síntesis.

Bueno, G. (1972) Ensayos materialista. Madrid: Taurus (Ensayistas 86).

Bueno, G. (1992-1993) Teoría del cierre categorial. Oviedo: Pentalfa.

Bueno, G. (1996) El sentido de la vida. Oviedo: Pentalfa.

Bueno, G. (1999) España frente a Europa. Barcelona: Alba Editorial.

Bueno, G. (1996) El animal divino. Ensayo de una filosofía materialista de la religión. Oviedo: Pentalfa.

Cimdiņa, A. (2014) Imants Ziedonis: piederības meklējumi, brīvības treniņš. Rīga: Zinātne.

García Berrio, A. (1984) Retórica como ciencia de la expresividad: presupuestos para una retórica general. Madrid: E.L.U.A.

Hurtado Albir, A. (2001) Traducción y traductología: introducción a la traductología. Madrid: Cátedra.

Katan, D. (1999) Translating Cultures. An introduction for Translators, Interpreters and Mediators. Manchester: St. Jerome.

Newmark, P. (1981) Approaches to translation. Oxford: Pergamon Press.

Nida, E. A. (1945) Linguistics and Ethnology in Translation Problem. Word, 2: 194-208. Disponible en https://www.tandfonline.com/doi/abs/10.1080/00437956.1945. 11659254 [Consultado el 8 de junio de 2019].

Nord, Ch. (1997) Translating as a Purposeful Activity. En F. Alves (ed.) Collecciò d'Estudis sobre la Traducciò, 3 (pp. 91-107). Castellón: Universitat Jaume I.

Vermeer, H.J. (1983) Translation theory and linguistics. En P. Roinila, R. Orfanos y S. TirkkonenCondit (eds.) Näkökohtia käänamisen tutkimuksesta (pp. 1-10). Kuopio: University of Joensuu.

Vlakhov, S. y Florin, S. (1970) Neperevodimoe v perevode: realii. En Masterstvo perevoda (pp. 432-456). Moscú: Sovetskii pisatel.

Zālīte, M. (2009) To mēs nezinām: sarunas ar Imantu Ziedoni. Rīga: Dienas Grāmata.

\section{RECURSOS DE ANÁLISIS EMPÍRICO}

Ziedonis, I. (2016) Krāsainās pasakas. Rīga: Zvaigzne ABC.

\section{THE TRANSLATION TO SPANISH OF IMANTS ZIEDONIS' COLORFUL TALES}

Abstract. Krāsainās pasakas (Colorful Tales), title that would be translated to Spanish as Cuentos de colores, has continually been one of the most popular works of Imants Ziedonis since it came to light in 1973. This set of lyrical miniatures, each of which has a color as an object was in principle aimed to children. In it the Latvian poet displayed a rich range of stylistic figures whose purpose was to contribute to the development of work that through play, beauty and intelligence served to the formation of the child. Among these figures we can find epithets, paradoxes, comparisons and parallelisms that interweave a subtly absurd and 
delightfully funny reality standing out through the text due to their recurrence and variety. The task of pouring into Spanish such a stylistic density while maintaining fidelity to the original as much as its elegance and naturalness, has not always been easy. The General Rhetoric as it has been reinterpreted in all its operations by Antonio García Berrio and Tomás Albadalejo, the scope of Philosophical Materialism as a philosophical system capable of accounting for reality in all its breadth and the translation theory of authors such as Nida, Newmark, Vlakhov, Florin and Hurtado Albir will serve us to give an account of some of the problems presented by the Spanish adaptation of Ziedonis' text.

Key words: Materialism, Rhetoric, Colorful Tales, translation, Ziedonis

Miguel Ángel Pérez Sánchez (Mag. Philol., Lector) trabaja actualmente en la Universidad de Letonia. Sus intereses académicos incluyen la Traducción literaria y la Teoría de la Literatura. Correo electrónico: mperezs10@gmail.com 